\title{
The ligamental scar in the costovertebral articulation of the tyrannosaurid dinosaurs
}

\author{
Tatsuya Hirasawa \\ Acta Palaeontologica Polonica 54 (1), 2009: 49-59 doi:http://dx.doi.org/10.4202/app.2009.0106
}

The costovertebral articulation is integral to constrain the thoracic kinematics and to infer the breathing mechanism in the respect with costal aspiration. However, the structure of the costovertebral articulation in non-avian theropods has not been studied in great detail before. This study highlights the Tyrannosauridae, which is represented by numerous complete specimens. Costovertebral articulations of ten tyrannosaurid specimens, including two nearly in-situ articulated fossils, were investigated and compared with those in extant Archosauria. For extant archosaurs, dissections were conducted to rationalize the soft tissue anatomy in tyrannosaurids. This study shows that the rib articulates ventrally or posteroventrally with the distal end of the corresponding vertebral transverse process in the tyrannosaurid ribcage. A ligament (ligamentum costotransversarium) can be reconstructed to connect the rib tuberculum to the transverse process in each articulation. The scar for lig. costotransversarium is recognizable in many theropod skeletons, and this rugosity can be used to identify the rotational axis for the rib. This result provides a cornerstone for exploring the evolution of the ribcage and breathing mechanisms across the theropod lineage leading to birds.

Key words: Theropoda, Tyrannosauridae, ribcage, vertebra, rib, soft tissue anatomy.

Tatsuya Hirasawa [hirasawa@eps.s.u-tokyo.ac.jp], Department of Earth and Planetary Science, Graduate School of Science, the University of Tokyo, 7-3-1 Hongo, Bunkyo-ku, Tokyo, 113-0033, Japan

This is an open-access article distributed under the terms of the Creative Commons Attribution License (for details please see creativecommons.org), which permits unrestricted use, distribution, and reproduction in any medium, provided the original author and source are credited. 
FoF Full text $(541.1 \mathrm{kB})$ 